\title{
Principio de sostenibilidad presupuestaria vs. principio de garantía de la seguridad social
}

Principle of budget sustainability vs. principle of social security guarantee

\author{
Magdalena Balestero Casanova \\ ORCID: 0000-0002-6562-9358 \\ Universidad Católica del Uruguay \\ Correo: magdalena.balestero@ucu.edu.uy
}

Recibido: 23/02/2021

Aceptado: 23/09/2021

Resumen: El objetivo es analizar la posibilidad de compatibilizar el principio de sostenibilidad presupuestaria con el principio de garantía de la seguridad social. Para ello, se mencionan las medidas de consolidación fiscal y equilibrio presupuestario que se suelen adoptar ante las crisis económico-financieras en aras de alcanzar estabilidad presupuestaria y sostenibilidad financiera. A su vez, se propone que el desafío es lograrlo sin afectar derechos sociales tales como los prestacionales y, en especial, la seguridad social cuando para dicho equilibrio se recurre a limitar el gasto público social, compatibilizando los principios de sostenibilidad presupuestaria y de garantía de la seguridad social.

Palabras clave: regla fiscal; sostenibilidad financiera y presupuestaria; derechos sociales prestacionales; gasto público social; garantías de seguridad social.

\begin{abstract}
The target is to analyze the possibility of make compatible the principle of budget sustainability with the principle of social security guarantee. In order to do so, it mentions fiscal consolidation measures and budget balance usually adopted after economic-financial crisis to reach budget stability and financial sustainability. It also proposes that the challenge is achieving it without affecting social rights, such as social benefits and social security, when, in order to reach such stability, it recurs to limit social public spending, making compatible the principles of budget sustainability and of social security guarantee.
\end{abstract}

Keywords: fiscal rule; financial and budget sustainability; social benefits rights; social public spending; social security guarantees. 


\section{Introducción}

Como consecuencia de las grandes crisis económico-financieras mundiales se observa una creciente preocupación por alcanzar la estabilidad presupuestaria, la sostenibilidad financiera, recurriendo a medidas de consolidación fiscal. En algunos países incluso el principio de sostenibilidad o equilibrio presupuestario se ha constitucionalizado.

No obstante, y como contracara de dichas crisis, en muchas sociedades peligra la protección de derechos sociales, entre ellos los prestacionales y en especial la seguridad social, ya que, entre dichas medidas, se recogen reglas tendientes a limitar el gasto público social.

Se propone analizar la compatibilización de los principios de sostenibilidad presupuestaria y de garantía de la seguridad social en una realidad socioeconómica comprometida y costosa. Para ello, se definen ciertos conceptos, elementos e institutos vinculados con el contenido de cada principio para arribar a ciertas conclusiones que, sin pretender poner fin al tema planteado, alienten a reflexionar al momento de resolver adoptar mecanismos económicos que afecten derechos sociales y, en especial, la seguridad social.

\section{Medidas de consolidación fiscal: reglas fiscales}

En primer lugar, se comienza por hacer referencia a ciertos conceptos económicos necesarios para poder elaborar y comprender lo que implica el principio de sostenibilidad presupuestaria.

Las crisis económico-financieras provocan un desequilibrio en las cuentas públicas y dejan como legado la necesidad de generar estrategias de acción cuya prioridad se centre en salvaguardar la estabilidad financiera y alcanzar una sostenibilidad presupuestaria. Concretamente, ese desequilibrio se visualiza en un descontrol del déficit público, desajustes entre ingresos y gastos públicos, incrementos de deuda pública, entre otros factores, y dan lugar a la aparición de mecanismos de consolidación fiscal o reglas fiscales.

Corresponde aclarar que no se realizará en el presente un análisis económico exhaustivo de las reglas fiscales, ya que excede el objeto. Simplemente, resulta relevante indicar, como lo hace Andrés Blanco (2020), que la regla fiscal como norma jurídica es una proyección normativa de la corriente neoclásica del pensamiento económico. En el 
presente, no se pretende la afiliación a ninguna teoría económica en particular, sino que se recurrirá a definiciones de las reglas fiscales más allá de la filiación clásica o neoclásica, o de teorías rivales de la neoclásica de la economía, como herramientas que apuntan a la estabilidad fiscal y recortes del gasto público. Ello, en aras de poder arribar al objeto del presente que es el enfrentamiento o compatibilización de los principios de sostenibilidad presupuestaria y el principio de garantía de la seguridad social.

Ahora bien, como primera aproximación al concepto de reglas fiscales, Blanco (2020) explica que bajo dicha denominación se pueden incluir normas jurídicas, constitucionales o legales, que establecen límites duraderos a ciertos elementos de las finanzas públicas, como ser la deuda pública y/o el gasto público.

Por ello, antes de avanzar, se estima pertinente detenerse en definir ciertos conceptos económicos claves para poder comprender el alcance de la terminología específica, para lo cual brevemente se formula la siguiente lista:

- Producto Interior Bruto (PIB): es el valor de todos los bienes y servicios finales producidos en la economía en un determinado periodo (un trimestre o un año). [...] Es el indicador básico de la actividad económica (Dornbusch \& Fischer, 1994, p. 9).

- Gasto de consumo: gasto que realizan las economías domésticas en compra de bienes y servicios para el consumo (Dornbusch \& Fischer, 1994, p. 41).

- Gasto público: es la suma de las transferencias que el Estado realiza a algunas personas sin recibir ningún servicio a cambio, como ser las prestaciones sociales y prestaciones por desempleo, y las compras de bienes y servicios por parte del Estado, como ser gastos destinados a defensa nacional, construcción de carreteras, y sueldos de funcionarios públicos. Se financia por medio de impuestos y endeudamiento (Dornbusch \& Fischer, 1994, pp. 43 у 661).

- Gasto público social: es el gasto que realiza el sector público financiado a través de la tributación o el endeudamiento (independientemente del organismo proveedor del servicio) para incidir positivamente en la calidad de vida de las personas, puede incluir educación, salud, seguridad social y asistencia social, vivienda y servicios comunitarios. 
- Gasto de inversión: es el que se produce por la inversión, es decir, por cualquier actividad realizada en un año que aumenta la capacidad de la economía para producir en el futuro, e incluye inversión física y en capital humano, como ser educación (Dornbusch \& Fischer, 1994, p. 43).

- Déficit presupuestario: se produce cuando los gastos totales del Estado (formado por compras de bienes y servicios y transferencias) exceden los ingresos del Estado (formado por los impuestos que este recauda). En general está ligado al presupuesto del Estado, ya que hace referencia al déficit fiscal previsto por el gobierno al realizar los presupuestos del periodo siguiente, normalmente un año (Dornbusch \& Fischer, 1994, p. 84).

- Déficit público: a veces se utiliza como sinónimo de déficit presupuestario, según el alcance del anterior en función de la realidad de cada país. Concretamente es cuando el Estado gasta más de lo que le ingresa por lo cual para encontrar una fuente de financiación ajena realiza emisiones de activos financieros, por ejemplo, emite títulos de deuda (letras del tesoro, bonos $\mathrm{u}$ obligaciones). Es una partida que mide la situación económica del Estado, mediante la diferencia entre ingresos y gastos en un año concreto, normalmente se expresa en términos de porcentaje sobre el PIB de ese año.

- Deuda pública: es la deuda total que mantiene un Estado con inversores particulares o con otro país, suele expresar en porcentaje del PIB de ese año.

Por su parte, Agustín García Serrador (2004, pp. 22-24), al referirse a las reglas fiscales indica que:

En sentido amplio, las reglas fiscales se pueden definir como el conjunto de normas y regulaciones con las que se elabora, aprueba e implementa el presupuesto (Alesina \& Perotti, 1999). En un sentido más estricto, sin embargo, y delimitando el concepto al que mejor representa la experiencia internacional, $[\ldots]$ se entiende la regla fiscal como aquella restricción constitucional o legislativa en la política fiscal que especifica algún tipo de límite en las variables fiscales, tales como saldo presupuestario, deuda, gasto o impuestos, y que se aprueba normalmente junto a una regulación del procedimiento de elaboración, discusión parlamentaria, ejecución y control del presupuesto (Kennedy, Robbins \& Delorme, 2001). 
Agrega que tienen como objetivo evitar o reducir el grado de discrecionalidad de la política fiscal para aumentar la disciplina e intentar reducir el déficit fiscal para alcanzar y mantener la consolidación fiscal. Sin perjuicio de lo cual se pueden esgrimir ciertos argumentos teóricos para la adopción de reglas fiscales por parte de muchos países en las últimas décadas:

- que las reglas fiscales facilitan el papel estabilizador de la política monetaria;

- que condicionan las medidas fiscales de los países miembros de un bloque regional, área o de un determinado nivel de gobierno;

- que apuntan a la equidad intergeneracional, de manera que las anteriores sirvan para contener el gasto corriente y no financiarlo mediante deuda, cuyo pago tendrían que efectuar las generaciones venideras;

- que su uso reduce el grado de discrecionalidad de los gobiernos, sobre todo cuando las autoridades fiscales carecen de reputación en cuanto a disciplina fiscal, cuando el gobierno pueda actuar de forma incoherente planteándose un problema de inconsistencia temporal, cuando los responsables de la política fiscal puedan estar influidos por grupos de presión o, por último, cuando puedan alterar sus decisiones fiscales por motivos electoralistas; todo lo cual influye en las expectativas de los agentes económicos, de forma que estos puedan predecir de manera más acertada la evolución de la política económica gubernamental y adoptar, en consecuencia, sus propias decisiones de ahorro, inversión o empleo, redundando en un mayor crecimiento económico, mayor empleo y estabilidad económica.

A su vez, cuando se produce acumulación de alto déficit público, no como consecuencia de variaciones cíclicas que pudieran sufrir los países, sino por motivos discrecionales o por otras variables no puramente económicas, como las derivadas del comportamiento de las instituciones presupuestarias, también resulta viable la adopción de mecanismos de consolidación fiscal para conseguir la estabilidad macroeconómica y la sostenibilidad fiscal, y reglas fiscales que aseguren su mantenimiento. No obstante, García Serrador (2004, p. 25) expresa que: 
La existencia de reglas no impide necesariamente por completo el papel estabilizador de la política fiscal, ya que en la propia regla se puede tener en cuenta la actuación de los estabilizadores automáticos [...]. Por otro lado, también se puede solucionar la falta de poder de estabilización mediante el uso de reglas con retroalimentación, de forma que las mismas pueden cambiar en función del estado de la economía, o con el establecimiento de cláusulas de escape, al permitir la adopción de medidas discrecionales ante ciertas circunstancias excepcionales.

Por su parte, Francisco Villar Rojas (2016) -catedrático de Derecho Administrativo en la Universidad de La Laguna (España) - expresa que cada factor económico puede explicar la adopción de determinada medida de consolidación fiscal mediante la juridificación de reglas vinculantes para todas las administraciones públicas, concretamente: la estabilidad presupuestaria frente al déficit público (estructural); la sostenibilidad financiera para reducir la deuda pública, tanto la financiera como la comercial; la regla de gasto para contener el crecimiento del gasto público y los compromisos que comporta. Y, analizando la Ley Orgánica de Estabilidad Presupuestaria y Sostenibilidad Financiera aprobada en España en 2012, afirma que: "Estas tres reglas constituyen los pilares de la política pública puesta en marcha para hacer frente al impacto de la crisis económico-financiera sobre las haciendas públicas", y que "La piedra angular del proceso de juridificación se encuentra en el reconocimiento constitucional de la estabilidad presupuestaria como principio rector de la acción de los poderes públicos". A su vez, da elementos para conceptualizar cada una de dichas reglas, se resumen las siguientes definiciones:

- Estabilidad presupuestaria: hace referencia a la situación de equilibrio o superávit estructural en términos de capacidad de financiación que se impone en forma anual o en el ciclo económico y que puede implicar que está prohibido incurrir en déficit estructural.

- Sostenibilidad financiera: refiere a la capacidad de cada administración pública para financiar compromisos de gastos presentes y futuros dentro de los límites de déficit, deuda pública y morosidad de deuda comercial, englobando tanto la deuda financiera - préstamos y deuda- como la deuda comercial -pagos a proveedores-. 
- Regla de gastos: implica la limitación del gasto público mediante el establecimiento de una tasa máxima (crecimiento nominal del PIB) por encima de la cual no es posible mayor gasto público, incluso aunque se tenga capacidad o liquidez, con el fin de evitar que en épocas de bonanza se asuman obligaciones que luego, en épocas de crisis, se conviertan en compromisos inasumibles.

\section{Principio de sostenibilidad presupuestaria}

El breve desarrollo realizado de las partidas y conceptos económicos permite arribar al principio de sostenibilidad presupuestaria que se entiende es producto de la conjugación de los diversos mecanismos de consolidación fiscal, surgiendo pues a la vida económica a partir de la existencia de reglas fiscales y consagrándose a nivel jurídico ante el convencimiento o convicción de su aparente necesaria existencia.

Podría definirse al principio de sostenibilidad presupuestaria como aquel que se refiere a la capacidad de cada Estado para financiar compromisos de gastos presentes y futuros dentro de los límites de déficit, deuda pública y morosidad de deuda comercial, en aras de alcanzar y mantener una situación de equilibrio presupuestario sin recurrir al endeudamiento más allá de cierto límite.

La consagración de este principio en los ordenamientos internos adopta diversas modalidades, llegando incluso a constitucionalizarse, ya sea en forma explícita o mediante la aprobación de medidas de consolidación fiscal o reglas fiscales que se consagran en el texto constitucional; o bien, debido a acuerdos intergubernamentales que fortalecen la coordinación de políticas presupuestarias e incluso imponiendo la adopción de reformas incisivas en la esfera interna económica y social.

\section{Derechos sociales prestacionales: seguridad social}

Corresponde hacer referencia al concepto de seguridad social, su ubicación en el esquema general de derechos fundamentales. Para luego poder dimensionar el alcance del otro principio objeto del presente trabajo: el principio de garantía de la seguridad social.

La seguridad social, en relación con los derechos fundamentales, se vincula o pertenece al área de los derechos económicos, sociales y culturales; y, a su vez, más precisamente, ingresa en los derechos sociales prestacionales. 
Los derechos sociales prestacionales, tal como lo explica Pietro Masala (2016), son considerados derechos financieramente condicionados, por fundarse en general en normas constitucionales programáticas que establecen una finalidad determinada, pero cuya garantía está condicionada a la implementación legislativa, que supone la ponderación de los intereses subyacentes con los demás intereses constitucionalmente protegidos, teniendo en cuenta los limites objetivos que el propio legislador encuentra en su implementación con respecto a los recursos organizativos y financieros disponibles.

Debido a estas características, para cierta parte de la doctrina (Zolo, 2001), los derechos sociales serian únicamente servicios sociales, prestaciones asistenciales ofrecidas discrecionalmente por los gobiernos para lograr una mayor integración, orden público e igualdad, por lo que se ha cuestionado su naturaleza misma como derechos fundamentales.

José Luis Rey Pérez (2007, pp. 137-138) respecto de la naturaleza de los derechos sociales refiere a que normalmente se los suele considerar como imperfectos, incompletos o de difícil realización; y que, frente a los de libertad, los derechos civiles y políticos, los sociales se presentan como derechos de segunda categoría. A su vez, expresa que esto puede deberse al momento en que históricamente aparecieron, ya que:

La evolución en la positivización de los derechos se suele decir que los sociales surgieron en lo que se conoce como el proceso de generalización, cuando las presiones de los movimientos obreros y la incorporación de los partidos de los trabajadores a los parlamentos gracias a la extensión del sufragio hicieron posible la entrada de pretensiones de igualdad real (y no solo formal) en el diseño de la política; pretensiones que se sustanciarían en un catálogo de derechos que, no obstante, no se vio garantizado y recogido de forma efectiva hasta después de la II Guerra Mundial con la aparición y el desarrollo de los estados de bienestar.

Aunque durante las décadas de crecimiento y asentimiento del Estado de bienestar, los derechos sociales comenzaron a verse como derechos irrenunciables que formaban parte del catálogo con la misma importancia que los derechos de libertad, la crisis que este modelo de Estado lleva viviendo desde los años setenta ha vuelto a poner sobre la mesa la cuestión de si los derechos sociales son auténticos derechos y no simples pretensiones bien intencionadas. 
Si bien es cierto que poseen características distintas las libertades, los derechos civiles y políticos y los derechos sociales, atendiendo a los valores morales que unos y otros tratan de proteger, no hay diferencia en su relevancia jurídica. En tal sentido, Rey Pérez (2007, pp. 155-156) manifiesta que:

Los valores que los derechos sociales tratan de proteger son universales. Intentan dar cobertura jurídica a la pretensión moral justificada de igualdad real, a la pretensión moral de que la idea de dignidad de las personas (esto es, la exigencia ética de tratarnos como fines y no como meros medios) demanda la satisfacción de una serie de necesidades básicas sin las cuales no podemos desarrollarnos: necesidad de alimentación, de vivienda, de salud, de protección, de pertenencia a una sociedad. Solo cuando tengamos cubiertas esas necesidades estaremos en condiciones de ejercitar nuestras libertades.

Y concluye que:

Los derechos sociales, en definitiva, sustraen del juego del mercado la satisfacción de las necesidades imprescindibles para la existencia. Por eso decía al principio que me gusta hablar de derechos de igualdad más que de derechos sociales, porque los dos grupos de derechos, los de igualdad y los de libertad, son sociales, tratan de hacer viable la vida en sociedad, un determinado tipo de vida que persigue el respeto a la igual dignidad de todas las personas. Y, por ello, en mi opinión, los dos son igualmente fundamentales, auténticos derechos humanos.

Se estima que, luego de que se han reconocido jurídicamente los derechos sociales, integrando el derecho positivo tanto en el derecho interno -en particular en las Constituciones-, como en el derecho internacional -en diversos instrumentos-, insistir con este cuestionamiento es un discurso estéril. Como remate de este tema, se transcribe a continuación el primer considerando del Preámbulo del Protocolo Adicional a la Convención Americana sobre Derechos Humanos en materia de Derechos Económicos, Sociales y Culturales, "Protocolo de San Salvador" (Organización de los Estados Americanos [OEA], 1988): 
Considerando la estrecha relación que existe entre la vigencia de los derechos económicos, sociales y culturales y la de los derechos civiles y políticos, por cuanto las diferentes categorías de derechos constituyen un todo indisoluble que encuentra su base en el reconocimiento de la dignidad de la persona humana, por lo cual exigen una tutela y promoción permanente con el objeto de lograr su vigencia plena, sin que jamás pueda justificarse la violación de unos en aras de la realización de otros.

Ahora bien, dentro del abanico de derechos sociales, se hace foco en la seguridad social, la cual, como bien indica Ricardo Barona Betancourt (2017, pp. 31-33), se ha definido de distintas formas, que se citan a continuación:

- Para el Centro Interamericano de Estudios de Seguridad Social (Ciess): La seguridad social es un conjunto de medidas que la sociedad proporciona a sus integrantes con la finalidad de evitar desequilibrios económicos y sociales que, de no resolverse, implicarían la reducción o la pérdida de los ingresos a causa de contingencias como la enfermedad, los accidentes, la maternidad o el desempleo, entre otras. La forma más común de identificar la seguridad social es mediante las prestaciones y la asistencia médica, sin embargo, esas son solo algunas de las formas en las que se presenta en la vida cotidiana. En los hechos, la seguridad social también se encuentra en los actos solidarios e inclusivos de las personas hacia los demás, pues esos actos llevan en sí mismos la búsqueda del bienestar social. En la actualidad, existe un consenso internacional respecto a la consideración de la seguridad social como un derecho humano inalienable, producto de casi un siglo del trabajo mancomunado de organismos internacionales relevantes, como la Organización Internacional del Trabajo (OIT), la Organización de las Naciones Unidas (ONU), e instituciones supranacionales, como la Asociación Internacional de Seguridad Social (AISS), la Organización Iberoamericana de Seguridad Social (OISS) y la Conferencia Interamericana de Seguridad Social (CISS).

- De acuerdo con la Red Internacional para los Derechos Económicos, Sociales y Culturales (RED-DESC): Todas las personas tienen derecho a la seguridad social. A través de la provisión de bienestar social o asistencia, los Estados deben garantizar la protección de todos, especialmente los miembros 
más vulnerables de la sociedad, en caso de desempleo, maternidad, accidente, enfermedad, invalidez, vejez u otras circunstancias de la vida. Los Estados deben realizar progresivamente el derecho a la seguridad social a través de medidas para ofrecer protección, a través de dinero en efectivo o en especie, que permita a los individuos y las familias adquirir la atención sanitaria al menos esencial, abrigo y vivienda básicos, agua y saneamiento, alimentación, y las formas más básicas de educación... Debido a su efecto redistributivo, el derecho a la seguridad social es un factor importante en la inclusión y la cohesión social, así como en la reducción de la pobreza. La seguridad social debe proporcionarse sobre una base no discriminatoria, aunque los medios de financiación y de proporcionar seguridad a la sociedad variarán de un Estado a otro.

- Análogamente, la OIT señala que: La seguridad social es la protección que una sociedad proporciona a los individuos y los hogares para asegurar el acceso a la asistencia médica y garantizar la seguridad del ingreso (al sistema de pensiones), en particular en caso de vejez, desempleo, enfermedad, invalidez, accidentes del trabajo, maternidad o pérdida del sostén de familia.

A su vez, para completar este marco conceptual, Barona Betancourt (2017, p. 34) agrega que Gustavo Arce Cano considera que el concepto de seguridad social:

Fue definido por primera vez en la Conferencia Internacional del Trabajo [CIT], reunida en Filadelfia en 1994, indicando que la seguridad social engloba un conjunto de medidas adoptadas por la sociedad para garantizarle a sus miembros la protección contra ciertos riesgos que el individuo con sus recursos módicos no puede cubrir.

Sin perjuicio de ello, la Declaración Universal de los Derechos Humanos (Naciones Unidas, 1948) expresa en su artículo 22:

Toda persona, como miembro de la sociedad, tiene derecho a la seguridad social, y a obtener, mediante el esfuerzo nacional y cooperación internacional, habida cuenta de la organización y los recursos de cada Estado, la satisfacción de los derechos económicos, sociales y culturales, indispensables a su dignidad y al libre desarrollo de su personalidad. 
Por su parte, el Pacto Internacional de Derechos Económicos, Sociales y Culturales (Naciones Unidas, 1966), en su artículo 9 expresa: "Los Estados parte en el presente Pacto reconocen el derecho de toda persona a la seguridad social, incluso al seguro social”. Es decir, lo reconoce, pero no desarrolla su contenido.

Asimismo, en el Sistema Interamericano de Derechos Humanos el Protocolo Adicional a la Convención Americana sobre Derechos Humanos en materia de Derechos Económicos, Sociales y Culturales, "Protocolo de San Salvador" (OEA, 1988), en su artículo 9 consagra el derecho a la seguridad social, pero además describe su contenido, en cuanto determina que:

1. Toda persona tiene derecho a la seguridad social que la proteja contra las consecuencias de la vejez y de la incapacidad que la imposibilite física o mentalmente para obtener los medios para llevar una vida digna y decorosa. En caso de muerte del beneficiario, las prestaciones de seguridad social serán aplicadas a sus dependientes. 2. Cuando se trate de personas que se encuentran trabajando, el derecho a la seguridad social cubrirá al menos la atención médica y el subsidio o jubilación en casos de accidentes de trabajo o de enfermedad profesional $\mathrm{y}$, cuando se trate de mujeres, licencia retribuida por maternidad antes y después del parto.

A modo de síntesis, y de conformidad con el planteo que realiza Roman Navarro Fallas (2002), la seguridad social posee las siguientes características:

- Es un derecho inherente a todo ser humano, a su dignidad, por lo que la sociedad en su conjunto y el Estado están obligados a respetarlo, promoverlo, garantizarlo y satisfacerlo.

- Es un derecho universal, porque pertenece a toda persona humana, en condiciones de igualdad y no discriminación, y obliga al Estado y a la sociedad a la universalidad de su cobertura.

- Es un derecho fundamental. La naturaleza fundamental del derecho se desprende del carácter indispensable de su contenido para el desarrollo pleno del ser humano. 
- El bien jurídico inherente al derecho es la seguridad. En efecto, se trata de un derecho a la seguridad de que si le afectan ciertas contingencias encontrará la protección necesaria para enfrentarlas. Se le denomina seguridad social por dos motivos: 1) porque esa seguridad se la ofrece la sociedad en su conjunto al individuo; 2) que se trata de una seguridad individual, pero de ella gozan todos, como miembros de la sociedad. La seguridad reposa en la solidaridad.

- Se trata de un derecho individual de carácter social. Se trata de un derecho donde la única forma de satisfacerlo o hacerla realidad es con el concurso de todos.

- Es un derecho de naturaleza prestacional. La seguridad social no supone atender la contingencia en sí misma sino la necesidad económica que ella produce, a través de prestaciones en dinero o en especie, a cargo del Estado o de los entes públicos competentes.

- Las prestaciones pretenden satisfacer una serie de necesidades que se consideran ineludibles para el desarrollo de una vida digna. El contenido de la prestación debe responder a la dimensión de la necesidad que la contingencia ocasiona.

- Es un derecho complejo. Se denomina derecho complejo a aquel derecho cuyo contenido es un conjunto de derechos. Es decir que a la interna del derecho a la seguridad social existen una serie de derechos, generalmente, aunque no exclusivamente, generados por el acaecimiento de cada contingencia: derecho a la atención médica, derecho a la seguridad en el trabajo, derecho a la jubilación, derecho a la salud, etc.

- Es un derecho exigible frente al Estado. El Estado es a quien le corresponde actuar con objetividad los intereses generales o públicos. Si el derecho a la seguridad social es un derecho fundamental, inherente a todo ser humano y que, además, solo es posible satisfacerlo mediante el concurso de todos, entonces, es el Estado, quien está obligado a satisfacerlo, indistintamente de que algunos de esos derechos concretos puedan exigírsele a otros sujetos del ordenamiento jurídico (públicos o privados). 


\section{Principio de garantía de la seguridad social}

Del análisis de todos los conceptos y definiciones referidos en el apartado anterior, surge que, necesariamente, la seguridad social como derecho social prestacional implica la adopción de medidas por parte del Estado, no para su consagración como derecho fundamental, sino para su eficacia y de modo de poder asegurar su protección y goce.

Por ello, el principio de garantía de la seguridad social emerge como premisa fundamental para asegurar la eficacia del derecho a la seguridad social. Según Rey Pérez (2007, pp. 141-142):

La eficacia pertenece a lo que se pueden denominar como garantías. Estas serían los diversos medios a través de los cuales los derechos se hacen efectivos; las garantías se utilizan aquí en un sentido distinto al de garantía institucional o al de garantía jurisdiccional (que Ferrajoli denomina garantía secundaria). Cuando digo que la eficacia pertenece a la institución de las garantías a lo que me refiero es a las garantías primarias, esto es, a los mecanismos a través de los cuales se realizan y se hacen efectivos los derechos. Las garantías están supeditadas a ellos porque lo que pretenden es hacer real y efectivo su contenido. [...] En mi opinión, toda la dimensión de la eficacia cae de lleno en la institución de las garantías que, estando muy cercana a los derechos, se encuentra supeditada a ellos. Ponerlas al mismo nivel significa que el derecho y la moral, que el reconocimiento de los derechos humanos, estaría supeditado a la economía [...]. Si las garantías son las diversas maneras en que un derecho puede satisfacerse, eso supone que son más variables que los derechos. En función del contexto histórico y económico, cada vez más cambiante, tendremos que ir adaptando las garantías para lograr que los derechos sean siempre eficaces.

Como todo principio, se define como conjunto de líneas directrices a seguir y considerar cada vez que en la mira esté la seguridad social; y, su objeto apunta pues a la eficacia de las medidas adoptadas por el Estado para consagrar y asegurar el conjunto de prestaciones mediante las cuales se procura dar al individuo un grado suficiente de bienestar para que desarrolle adecuadamente su personalidad en beneficio propio y de la sociedad, sobre la base de una adecuada participación y racional utilización de los recursos de la seguridad social, de modo de que su alcance sea universal, esto es que ante 
la misma circunstancia o contingencia, los beneficiarios reciban igual posibilidad de cobertura.

A su vez, este principio se complementa con los principios que informan al sistema de seguridad social, que Navarro Fallas (2002) sintetiza de este modo:

1. El principio de universalidad subjetiva (todos los sujetos) y objetiva (todas las prestaciones) y la garantía de igualdad y no discriminación son un corolario de la titularidad del derecho. En efecto, si todo ser humano, por el solo hecho de pertenecer al género humano e integrar la sociedad, tiene derecho a la seguridad social, entonces, esta debe garantizársele a todo ser humano en el momento en que la contingencia sobrevenga.

2. El principio de solidaridad es una garantía que se deriva de la naturaleza social del derecho. Redistribución de recursos entre quienes los tienen en un período determinado y quienes no los tienen en ese mismo período: del empleado al desempleado, del sano al enfermo, del activo al jubilado; así como redistribuyendo los recursos entre las generaciones presentes para atender las necesidades de las pasadas (reparto), o bien disfrutando una protección razonable para no lesionar a las generaciones futuras.

3. El principio de integralidad es una garantía derivada del bien jurídico del derecho y de la dignidad humana. La sociedad no le brinda ninguna seguridad a la persona, si se dejan consecuencias (necesidades) importantes sin cubrir (por ejemplo, servicios hospitalarios, intervenciones quirúrgicas de alto coste, etc.).

4. El principio de subsidiariedad es una consecuencia de que el derecho reposa tanto sobre la responsabilidad individual como social (principio de responsabilidad). Este principio genera el equilibrio entre equidad y solidaridad en la financiación y en la protección (prestaciones).

5. El principio de la inmediatez es un corolario o exigencia que se deriva de la naturaleza de la contingencia. Si la protección, cobertura o prestación no se brinda oportunamente, se está lesionando el bien jurídico que el derecho contiene (la seguridad social). 
A su vez, recogiendo las recomendaciones y directrices contenidas en los instrumentos internacionales, se considera que otro elemento que nutre este principio es el desarrollo progresivo. Este concepto es recogido a texto expreso en el artículo 26 de la Convención Americana de Derechos Humanos (OEA, 1969):

Los Estados parte se comprometen a adoptar providencias, tanto a nivel interno como mediante la cooperación internacional, especialmente económica y técnica, para lograr progresivamente la plena efectividad de los derechos que se derivan de las normas económicas, sociales y sobre educación, ciencia y cultura, contenidas en la Carta de la Organización de los Estados Americanos, reformada por el Protocolo de Buenos Aires, en la medida de los recursos disponibles, por vía legislativa y otros medios apropiados.

El principio de garantía de la seguridad social debe pues integrar entre sus propósitos, la progresividad como elemento a considerar y evaluar al adoptar nuevas medidas que de modo alguno afecten la seguridad social y la salvaguarda de los derechos sociales ya adquiridos.

\section{Punto de contacto: ponderación no colisión}

En épocas de crisis económicas, si un Estado destina gran parte de su presupuesto a gasto público social, es cuando más peligra la garantía de los derechos sociales.

En el afán de la salvaguarda de la estabilidad financiera, un Estado puede verse en la situación de tener que asumir compromisos nacionales y/o internacionales que le impongan la adopción de reformas en la esfera económica y social; o también, puede que debido a mecanismos de consolidación fiscal vea en cierta forma condicionada su dirección política en lo que respecta a la contención del gasto público, en especial, el gasto público social.

Es en este punto, precisamente, que se ponen en contacto el principio de sostenibilidad presupuestaria y el principio de garantía de la seguridad social, y, según el contexto social, económico y jurídico del Estado en cuestión, habrá una colisión de principios o será viable su complementación. La encrucijada se resume en la ponderación de la exigencia de salvaguarda de la estabilidad financiera que reposa sobre el principio de sostenibilidad presupuestaria, y la eficacia y protección de los derechos sociales prestacionales, sobre la que se asienta el principio de garantía de la seguridad social. 
Al respecto, Masala (2016, p. 251), luego de analizar la evolución de la jurisprudencia de la Corte Constitucional italiana en materia de ponderación entre los derechos sociales prestacionales y la estabilidad presupuestaria, concluye que:

El legislador, al perseguir la estabilidad financiera, debe siempre orientarse no solo por el principio de igualdad-razonabilidad, sino también por un criterio de una más estricta proporcionalidad y por el conjunto de principios fundamentales del ordenamiento constitucional que incluyen la igualdad sustancial, la solidaridad y la salvaguardia de los derechos sociales.

A su vez, en esta ponderación todos los Poderes del Estado juegan un rol particular pero complementario. El Poder Legislativo y Poder Ejecutivo han de indicar la manera de cubrir los gastos asociados a la seguridad social, y, el Poder Judicial ante acciones regresivas en cuanto a la protección de los derechos es quien ha de ponderar y evaluar con lógica y criterio jurídico su legitimidad. En efecto, en la dialéctica que se entable detrás de una medida de consolidación fiscal, puede que en su implementación el principio de sostenibilidad presupuestaria se imponga, y, consecuentemente, se aprueben medidas que impliquen cierta regresividad respecto de la eficacia de los derechos sociales prestacionales. No obstante, para ello, invocando en definitiva el principio de garantía de la seguridad social, dichas medidas pueden ser mitigadas, incluso incursionando en la posibilidad de reclamar judicialmente contra el Estado, conforme los procesos disponibles en la normativa interna, pudiendo ir por la vía de la acción de amparo de reunirse los requisitos correspondientes. También, eventualmente, de ser el caso de que haya una regla fiscal recogida en una norma legal, que sea la piedra de toque para el enfrentamiento de los principios referidos, según cada orden interno se podrá manejar recurrir a la declaración de inconstitucionalidad -de darse los elementos formales pertinentes-, partiendo de la base del reconocimiento y tutela constitucional de los derechos sociales y a la seguridad social que pueden verse amedrentados.

Es por ello que, la progresividad en los avances en materia de derechos sociales se suele ver como una restricción a la autonomía legislativa, cuando en realidad no es más que el producto del diálogo que se debe entablar entre ambos principios objeto de estudio, y que permite elaborar ciertas reglas o pautas que harían viables medidas regresivas para surtir el análisis de la progresividad, como ser: i) que la medida sea justificada y proporcional; ii) que no desconozca situaciones particulares ya consolidadas; y iii) que en el evento de afectarlas prevea alternativas como regímenes de transición que protejan 
los derechos adquiridos y las expectativas legítimas (Goyes Moreno \& Hidalgo Oviedo, 2012).

En tal sentido, cuando como consecuencia de una regla fiscal de control de gasto público social se adopten medidas regresivas que imponen sacrificios o hacen que resulte gravosa la situación para individuos en el goce de derechos sociales prestacionales, se podría concluir que su legitimidad dependerá de ciertos requisitos:

- que sean medidas cuya justificación radica en la salvaguarda del equilibrio financiero;

- que sean necesarias y proporcionadas, de modo que la adopción de cualquier otra política o la omisión de actuar por parte del Estado sería más perjudicial para los derechos sociales en cuestión;

- que posean una duración razonable, es decir, que sean medidas temporales y/o provisorias, que abarquen solamente el periodo de crisis económica;

- que no sean discriminatorias y sus efectos se repartan en forma racional entre diferentes categorías de individuos afectados, guardando cierta proporcionalidad;

- que aseguren la protección del contenido mínimo esencial de los derechos sociales involucrados, o al menos un piso de protección social.

Dichos requisitos contemplan las recomendaciones del Comité de DESC, que al respecto, según explicita Víctor Bazán (2016), ha sostenido:

Existe una fuerte presunción de que la adopción de medidas regresivas con respecto a la seguridad social está prohibida de conformidad con el Pacto. Si se adoptan medidas deliberadamente regresivas, corresponde al Estado parte la carga de la prueba de que estas medidas se han adoptado tras un examen minucioso de todas las alternativas posibles y de que están deliberadamente justificadas habida cuenta de todos los derechos previstos en el Pacto, en el contexto del plano aprovechamiento del máximo de los recursos de que dispone el Estado parte. 
En efecto, el Comité de DESC ha formulado planteos sobre los criterios de las políticas de austeridad y otras asumidas por los Estados en tiempos de crisis económica, los que recogen los requisitos referidos.

En definitiva, la aprobación de medidas de consolidación fiscal, para asegurar o tender a una estabilidad financiera, sobre la base del principio de sostenibilidad presupuestaria, se legitima si se pondera preservar la eficacia de los derechos sociales prestacionales; y, si en caso de ser regresivas cumplen con ciertos requisitos y prevén reglas para mitigar sus consecuencias.

\section{Conclusiones}

La realidad económica es cambiante, pero los derechos permanecen y se desarrollan progresivamente, y por ello las garantías de los derechos han de adaptarse. La amalgama entre ambos aspectos es la clave.

Todos los derechos, su acceso, protección y garantía, poseen costos asociados. La estabilidad económica y financiera de un Estado permite el goce y desarrollo de un conjunto de libertades y derechos; pero para alcanzar tal objetivo hay que evitar la colisión o vulneración de otros derechos, como suele suceder con los derechos sociales prestacionales por su reconocimiento en normas programáticas y ser considerados derechos financieramente condicionados.

Por ello, el equilibrio ha de estar en aprobar medidas e institutos que contemplen y respeten los derechos, haciendo efectivos sus contenidos, de la forma económicamente más rentable, en atención al contexto socioeconómico en donde se van a aplicar. De no ser posible, es válido plantearse las diversas hipótesis de justiciabilidad de los derechos sociales afectados.

En general, las realidades de los sistemas de seguridad social resultan ser deficitarios, por lo cual el Estado debe hacer transferencias para cubrir la diferencia entre ingresos y egresos, lo que implica una presión adicional a las cuentas públicas. Consecuentemente, la seguridad social resulta ser campo fértil para justificar medidas regresivas en aras de cumplir con los objetivos fiscales.

No obstante, más allá de la relevancia económica y fáctica de la aprobación de una regla fiscal que refiera al control del gasto, concretamente cuando esta implique austeridad y control del gasto público social, lo importante es que las medidas dirigidas a salvaguardar la estabilidad financiera superen un control de razonabilidad y contemplen la protección y garantía que la seguridad social merece. 


\section{Referencias}

Barona Betancourt, R. (2017). Protección de la seguridad social en el sistema interamericano de derechos humanos. Páginas de seguridad social, 1(1), 31-59.

Bazán, V. (2016). Los derechos sociales en épocas de emergencias y crisis económicas. Anuario de Derecho Constitucional Latinoamericano, año XXII, (pp. 571-600). Bogotá: Colombia. Recuperado de https://es.scribd.com/document/450771367/Anuario-de-Derecho-ConstitucionalLatinoamericano-2016-Pdf-pdf

Blanco, A. (2020). Las reglas fiscales y la constitución uruguaya. Revista de la Facultad de Derecho, 49. doi: 10.22187/rfd2020n49a7

Dornbusch, R. \& Fischer, S. (1994). Macroeconomía (6 ${ }^{\mathrm{a}}$ ed.). Madrid: McGraw-Hill.

España. (2012, abril 27). Ley Orgánica 2/2012: Estabilidad Presupuestaria y Sostenibilidad Financiera. Boletín Oficial del Estado, 103. Recuperado de https://www.boe.es/eli/es/lo/2012/04/27/2/con

García Serrador, A. (2004). Teoría General sobre reglas fiscales. Quaderns de Política Económica, 8, 21-37. Recuperado de http://www.uv.es/poleco

Goyes Moreno, I. \& Hidalgo Oviedo, M. (2012). ¿Los principios del derecho laboral y la seguridad social dinamizan la jurisprudencia constitucional en Colombia? Entramado, 8(2), 168-183.

Masala, P. (2016). El impacto de la crisis económica y de la reforma constitucional de 2012 en la jurisprudencia de la Corte Constitucional italiana en materia de ponderación entre los derechos sociales prestacionales y la estabilidad presupuestaria. Anuario Iberoamericano de Justicia Constitucional, 20, 223255. doi: http://dx.doi.org/10.18042/cepc/aijc.20.08

Naciones Unidas. (1948, diciembre 10). Declaración Universal de los Derechos Humanos. Recuperado de https://www.un.org/es/about-us/universal-declarationof-human-rights

Naciones Unidas. (1966, diciembre 16). Pacto Internacional de Derechos Económicos, Sociales y Culturales. Recuperado de https://www.ohchr.org/sp/professionalinterest/pages/cescr.aspx

Navarro Fallas, R. A. (2002). El derecho fundamental a la seguridad social, papel del estado y principios que informan la política estatal en seguridad social. Revista de ciencias administrativas y financieras de la seguridad social, 10(1).

Recuperado de https://www.scielo.sa.cr/scielo.php?script=sci_arttext\&pid=S140912592002000100002

Organización de los Estados Americanos [OEA]. (1969, noviembre 22). Convención Americana de Derechos Humanos "Pacto de San José de Costa Rica". Recuperado de https://www.refworld.org.es/docid/57f767ff14.html 
Organización de los Estados Americanos [OEA]. (1988, noviembre 17). Protocolo Adicional a la Convención Americana sobre Derechos en materia de Derechos Económicos, Sociales y Culturales, "Protocolo de San Salvador". Recuperado de https://www.oas.org/es/sadye/inclusion-social/protocolo-ssv/docs/protocolo-sansalvador-es.pdf

Rey Pérez, J. L. (2007). La naturaleza de los derechos sociales. Derechos y Libertades, 16, 137-156. Recuperado de https://www.corteidh.or.cr/tablas/r23426.pdf

Villar Rojas, F. J. (2016). Implicaciones de los principios de sostenibilidad y estabilidad presupuestaria en los modos de gestión de los servicios públicos locales. El Cronista del Estado Social y Democrático de Derecho, 58-59, 96-106.

Zolo, D. (2001). Libertad, propiedad e igualdad. En Ferrajoli, L. (Autor), Los fundamentos de los derechos fundamentales (pp. 75-104). Madrid: Trotta.

\section{Contribución autoral}

a) Concepción y diseño del trabajo; b) Adquisición de datos; c) Análisis e interpretación de datos; d) Redacción del manuscrito; e) revisión crítica del manuscrito.

M. B. C. ha contribuido en a, b, c, d, e.

Editora científica responsable: Dra. María Paula Garat. 